\title{
Hassas Nokta Konumlama Yönteminin Doğruluğunun Mikro-Jeodezik Bir Ağda İncelenmesi
}

\author{
Investigating Accuracy of Precise Point Positioning Method in a Micro-Geodetic Network
}

\author{
Sefa YALVAÇ* \\ Gümüşhane Üniversitesi, Mühendislik ve Doğa Bilimleri Fakültesi, Harita Mühendisliği Bölümü, 29100, Gümüşhane
}

\begin{tabular}{lll}
\hline -Geliş tarihi / Received: 25.03 .2019 & •Düzeltilerek geliş tarihi / Received in revised form: 02.05.2019 • Kabul tarihi / Accepted: 16.05 .2019 \\
\hline
\end{tabular}

\begin{abstract}
$\ddot{O} z$
Bu çalışmada, Hassas Nokta Konumlama (HNK) yönteminin yatay ve düşey bileşen için doğruluğu incelenmiştir. Bu amaçla, 5 noktalı mikro-jeodezik bir ağ tesis edilerek ardışık üç gün 8 saatlik Global Navigation Satellite System (GNSS) oturumları gerçekleştirilmiş̧ir. Aynı zamanda bu ağda, noktalar arasındaki baz uzunluğu değerleri Elektronik Uzunluk Ölçer (EUÖ) ile yükseklik farkları ise geometrik nivelman yöntemi ile gidiş-dönüş şeklinde ölçülmüştür. Yüksek doğrulukta olduğu kabul edilen (yatayda $3 \mathrm{~mm}$ düşeyde ise birkaç $\mathrm{mm}$ ) klasik yersel ölçümlerden elde edilen sonuçlar HNK ve rölatif GNSS analizi sonuçlarıyla karşılaştırılmıştır. Yapılan karşılaştırmalar sonucunda, rölatif GNSS analiz sonuçlarından elde edilen değerlerin klasik yöntemden elde edilen değerlerle yatayda 1-6 mm düşeyde ise 10-20 $\mathrm{mm}$ seviyelerinde yakınlaştığı görülürken, HNK yöntemi için ise aynı değerlerin yatayda 1-28 mm düşeyde ise 50-80 $\mathrm{mm}$ seviyelerinde değişiklik gösterdiği tespit edilmiştir. Söz konusu değişimlere ait standart sapma değerlerinin ise rölatif konum belirleme için yatayda $\pm 2.20 \mathrm{~mm}$, düşeyde $\pm 16.46 \mathrm{~mm}$ olduğu, HNK yöntemi için ise yatayda $\pm 11.43 \mathrm{~mm}$ düşeyde ise $\pm 59.48 \mathrm{~mm}$ seviyelerinde olduğu görülmüștür.
\end{abstract}

Anahtar kelimeler: Doğruluk, HNK, GNSS, Mutlak Konumlama, Rölatif konumlama

\begin{abstract}
In this study, the accuracy of Precise Point Positioning (PPP) method was investigated. For this purpose, a microgeodetic network containing 5 stations was established and 8-hour GNSS Global Navigation Satellite System (GNSS) sessions for three consecutive days were performed. At the same time, the baselines between the stations in this network were measured by Electronic Distance Meter (EDM) and the height differences are measured by the geometric leveling method. The results obtained from classical terrestrial measurements, which are considered to be highly accurate (3 mm in horizontal and few mm invertical), were compared with the results of PPP and the relative GNSS methods. As a result of the comparisons, it was seen that the values obtained from the relative GNSS analysis approximated with the classical method with the levels of 1-6 $\mathrm{mm}$ in the horizontal and 10-20 mm in the vertical direction. For the PPP method, it was seen that the same values varied between $1-28 \mathrm{~mm}$ in horizontal and $5-8 \mathrm{~cm}$ in the vertical component. The standard deviation values of these changes were determined as $\pm 2.20 \mathrm{~mm}$ in horizontal and $\pm 16.46 \mathrm{~mm}$ in vertical for the relative positioning technique and $\pm 11.43 \mathrm{~mm}$ in the horizontal and $\pm 59.48 \mathrm{~mm}$ in vertical component for PPP method.
\end{abstract}

Keywords: Accuracy, PPP, GNSS, Absolute Positioning, Relative Positioning

* Sefa YALVAÇ; sefayalvac@gmail.com; Tel: (0456) 23310 00; orcid.org/0000-0002-8989-6231 


\section{Giriş}

Hassas Nokta Konumlama (HNK) yöntemi tek bir GNSS alıcısı kullanarak, doğrudan uydu ve alıcı arasındaki mesafenin belirlenmesi esasına dayanır. Bu yöntem global ölçekte koordinatların belirlenmesine imkan verdiğinden, rölatif konum belirlemede olduğu gibi referans sistem belirlemek için bölgesel istasyonların kullanımı zorunluluğu da yoktur. Bu teknikle yapılan konum belirleme için birçok ücretsiz yazılım ve çevrimiçi servis hizmet vermektedir. Oldukça basit ara yüzlü olan bu servisleri kullanmak için GNSS analizi konusunda deneyim ve ileri seviye bilgi sahibi olmaya da gerek yoktur (Abd-Elazeem vd., 2011; Zhou vd., 2018). HNK yöntemi, operasyonel kolaylık, düşük maliyet, sabit istasyon zorunluluğunun olmamas1, analizlerin hızlı ve kolaylıkla yapılması gibi birçok nedenden dolayı, HNK son yıllarda oldukça popüler olarak kullanılan bir konum belirleme yöntemidir.

GNSS uydularının sayısının artmas1, modernizasyonu ve IGS (International GNSS Service) başta olmak üzere, Jet Propulsion Laboratory (JPL), Center for Orbit Determination in Europe (CODE), GFZ (German Research Center for Geoscience) gibi hassas saat ve yörünge parametrelerini üreten ajansların artmasiyla birlikte, HNK yönteminin doğruluğu da buna paralel olarak ciddi seviyelerde artış göstermiş bulunmaktadır (Yiğit vd., 2016). Ancak yine de elde edilen doğruluk, dm-cm seviyelerinde olup, ölçü süreleri bazlı karşılaştırıldığında, halen rölatif konumlama yöntemi doğruluğuna ulaşılabilmiş değildir (Bahadur ve Nohutçu, 2018; Alkan vd., 2017). Ancak uydu jeodezisi ve veri değerlendirme stratejilerindeki yeni gelişmeler 1şığında bilim insanlarının çalışmaları bu konuda halen devam etmektedir. $\mathrm{Bu}$ nedenle, günümüzde $\mathrm{HNK}$ yönteminin doğruluğu sürekli gelişmekte olup, sürekli takip edilmesi gereken bir konudur.

Literatürdeki çalışmalar incelendiğinde, HNK yöntemi hakkındaki çalışmaların daha çok yöntemi kısıtlayan, yakınsama süresi (Bisnath ve Gao, 2009; Yao vd., 2013), çoklu GNSS çözümlerinin yöntemin duyarlılığına ve yakınsama süresine olan katkısı (Yiğit vd., 2016; Cai vd., 2015), troposferik ve iyonosferik hataların (Su ve Jin, 2018; Shi vd., 2012) koordinat kestirimine olan etkisi gibi konular üzerinde yoğunlaştığı görülmektedir. HNK yönteminden elde edilen sonuçların yüksek doğruluklu yöntemlerle karşılaştırılması üzerine odaklanan çalışmaların literatürde oldukça az olduğu görülmektedir (Marques vd., 2018).

$\mathrm{Bu}$ çalışmada, HNK yönteminin yatay ve düşey yönlü bileşenler için nokta konum doğruluğu incelenmiştir. $\mathrm{Bu}$ amaçla, 5 noktalı bir mikrojeodezik ağ tesis edilmiş ve ardışık üç gün en az 8 saatlik GNSS oturumları eşliğinde ölçülmüştür. Söz konusu ağda, GNSS oturumlarına ek olarak klasik yersel yöntemlerle de ölçüler gerçekleştirilmiştir. GNSS gözlemleri, rölatif ve HNK yöntemlerine göre ayrı ayrı analiz edilerek elde edilen sonuçlar yüksek doğrulukta gerçekleştirilen klasik yersel yöntemlerden elde edilen değerlerle karşılaştırılmıştır. Analizler sonucunda hesaplanan koordinat farkl11ıkları incelenerek HNK yönteminin doğruluğu irdelenmiştir.

\section{Yöntem}

HNK yönteminin doğruluğunu test etmek amaciyla Gümüşhane Üniversitesi Merkez kampüsü içerisinde 5 noktalı bir mikro-jeodezik ağ tesis edilmiştir. Söz konusu ağda ardışı 3 gün GNSS oturumları düzenlenmiş, aynı zamanda klasik yersel ölçmeler eşliğinde noktalar arasındaki baz uzunlukları ve yükseklik farkları elde edilmiştir. Yüksek doğrulukta olduğu kabul edilen klasik yersel ölçümlerden elde edilen sonuçlar farkları alınmak suretiyle, rölatif ve HNK yöntemlerinden elde edilen değerler ile karşılaştırılmıştır.

\subsection{Rölatif GNSS analizlerinin gerçekleş̧irilmesi}

GNSS oturumlarından elde edilen gözlemler GAMIT/GLOBK V10.7 yazılımında değerlendirilmiştir (Herring vd., 2019). Analizler temel olarak iki aşamadan oluşmaktadır. Bunlardan ilki GAMIT modülü ile günlük çözümlerin sağlanmasıdır. GAMIT modülü ile çözümler, her istasyonda eş zamanlı kaydedilen faz gözlemlerinden (L1 ve L2) oluşturulan iyonosferden bağımsız kombinasyonlar (LC) ile minimum zorlama esasında en küçük kareler yöntemine göre yapılmaktadır. Günlük çözümler için hassas yörünge ve saat parametreleri IGS (International GNSS Service)'den elde edilmiştir. İkinci aşamada, günlük bazda yapılan çözümler için referans sistem tanımlaması gerçekleştirilir. $\mathrm{Bu}$ amaçla, yazılıma ait GLORG modülü kullanılarak, koordinatları ve hızları ITRF sisteminde tanımlı IGS istasyonları vasitasıly, günlük çözümler Helmert transformasyonu ile ITRF sistemine taşınır. 


\subsection{Mutlak GNSS analizlerinin gerçekleştirilmesi}

Mutlak yöntemle yapılan GNSS analizleri HNK yöntemi ile gerçekleştirilmiştir. $\mathrm{Bu}$ amaçla, GAMP (GNSS Analysis software for Multiconstellation and multi-frequency Precise positioning) yazılımı kullanılmıştır. GAMP yazılımı, ANSI-C programlama dilinde yazılmıs, RTK LIB kütüphanesinin revize edilmesi ile oluşturulmuş, çoklu navigasyon sistemlerinin verilerinin kullanılmasına da imkan veren, $\mathrm{HNK}$ yöntemine göre koordinat kestirimi yapan bir yazılımdır (Zhou vd., 2018).

GAMP yazılımında, analizlerin hangi esaslara göre gerçekleştirileceği bir parametre girdi dosyası yardımıyla yapilır. Kullanıcilar bu dosya yardımıyla, analiz tipi (statik, kinematik), uydu yükseklik açısı, hangi uydu sistemlerinin kullanılacağı (tekli ya da çoklu), iyonosferik düzeltme dosyası ve yörünge dosyası seçimi, sonuçların hangi esaslara göre filtreleneceği vb. birçok konuda seçim yapabilirler.

\section{Uygulama}

\subsection{Nokta tesisi ve ölçülerin elde edilmesi}

Söz konusu bölge topoğrafik anlamda yüksek engebeli olduğundan, nokta yerlerinin seçiminde gökyüzünü açık bir şekilde görebilmesine imkan verecek yerlerin seçilmesine özen gösterilmiştir. Yine de Gümüşhane ilinin vadi (iki dağ arasına yerleșim göstermesi) niteliğinde olması sebebiyle, açık gökyüzünün tamamına erişim mümkün olmamıştır.

Nokta tesisleri, demir plaka üzerine sabitlenmiş $12 \mathrm{~cm}$ uzunluklu ve $14 \mathrm{~mm}$ yarıçaplı vidaların yere epoksi (kuvvetli yapıştırıcı) ile sabitlenmesi suretiyle yapılmıştır. Nokta konumlarını gösteren Google Earth görüntüsü Şekil 1'de sunulmuştur.

Tesisi yapılan noktalarda 2018 y1lının 110., 111. ve 112. günlerinde 8 saatlik GNSS oturumları gerçekleştirilmiştir.

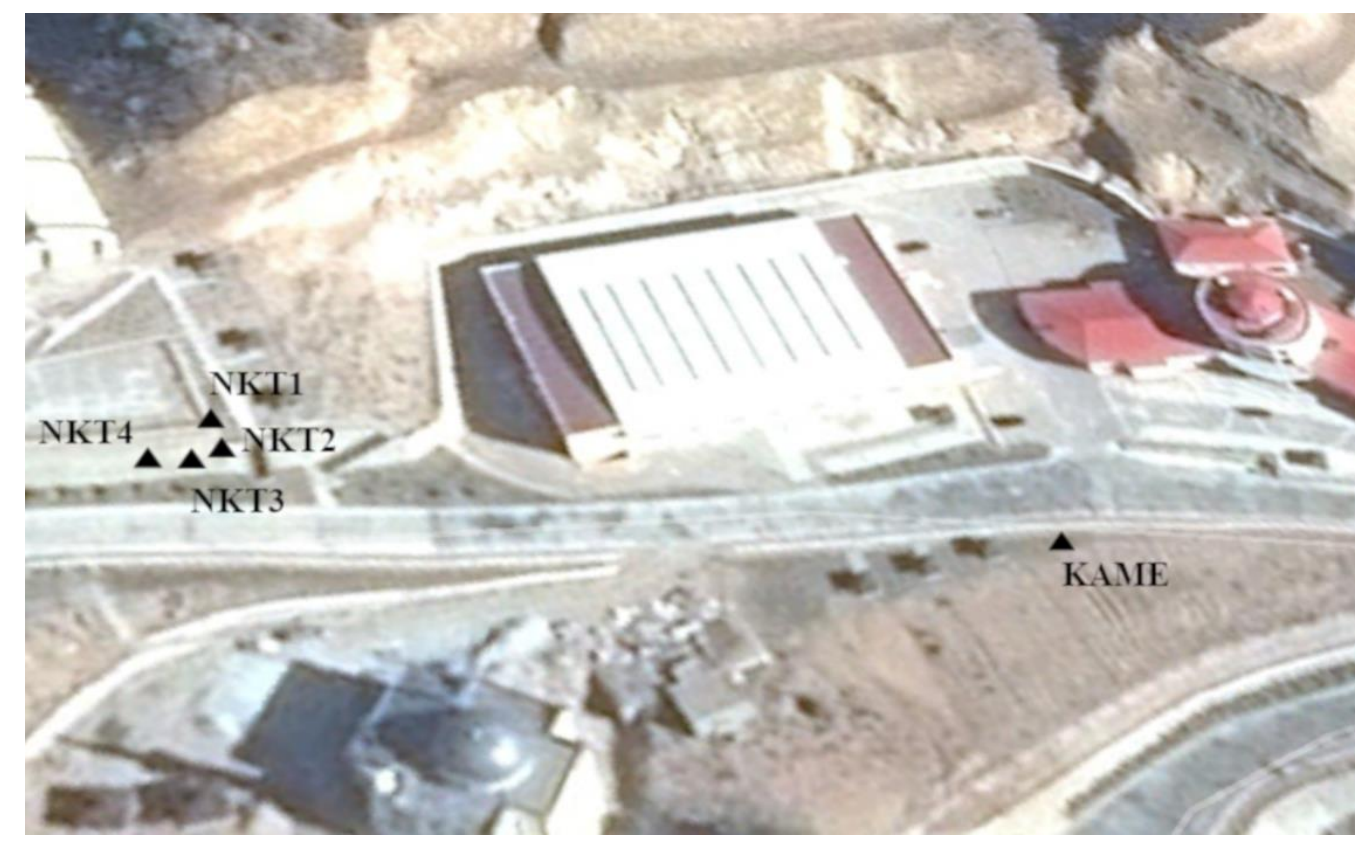

Şekil 1. Tesis edilen mikro-jeodezik ağın görünümü

Oturumlar JAVAD TRIUMPH-2 ve JAVAD Sigma 3A marka ve modelli GNSS alıciları ile 5 saniye kayıt sıklığı ve 10 derece uydu yükseklik açısında gerçekleștirilmiștir. Ölçümler sonucu elde edilen ham veriler TEQC (Translating Editing and Quality Check) yazılımı yardımıla RINEX (Receiver Independence Exhange) formatına dönüştürül-müştür.

\subsection{Jeodezik ă̆ın klasik yersel tekniklerle ölçülmesi}

KAME istasyonu ile diğer noktalar arasındaki baz uzunlukları ve yükseklik farkları klasik yersel tekniklerle elde edilmiştir. $\mathrm{Bu}$ amaçla, KAME noktasindan NKT1, NKT2, NKT3 ve NKT4 noktalarına Nikon DTM-332 marka ve modelli 
hassasiyeti $\sigma= \pm\left(3+2 \mathrm{ppm}^{*} \mathrm{~S}\right) \mathrm{mm}$ olan EUÖ (Elektronik Uzunluk Ölçer) ile yatay mesafe ölçümleri (ölçü düzleminde) gerçekleştirilmiştir (Nikon DTM-322, 2019). Yükseklik farkları ise yine aynı noktalar arasinda geometrik nivelmandan elde edilmiştir. Elde edilen sonuçlar Tablo 1'de sunulmaktadır.

Tablo 1. Klasik yersel ölçmelerden elde edilen baz uzunlukları ve yükseklik farkları (metre biriminde)

\begin{tabular}{llll}
\hline D.N & B.N & $\begin{array}{c}\text { Yatay mesafe } \\
(\mathbf{S})\end{array}$ & $\begin{array}{c}\text { Yükseklik farkı } \\
(\mathbf{d h})\end{array}$ \\
\hline KAME & NKT1 & 109.376 & -21.844 \\
KAME & NKT2 & 107.318 & -21.767 \\
KAME & NKT3 & 110.691 & -21.767 \\
KAME & NKT4 & 115.501 & -22.132 \\
\hline
\end{tabular}

\subsection{Rölatif ve Mutlak GNSS analizlerin gerçekleştirilmesi}

Rölatif GNSS analizleri GAMIT modülü kullanılarak minimum zorlama (KAME) esasında en küçük kareler yöntemine göre yapılmıştır. A zorlaması yatayda ve düşeyde $5 \mathrm{~cm}$ seviyeyle yapılmış ve günlük çözümler yatayda 3-6 mm düşeyde 10-15 mm hassasiyetinde elde edilmiştir. Daha sonra GLORG modülü kullanılarak, koordinatları ve hizları ITRF sisteminde tanımlı 10 IGS istasyonu vasitasıyla, günlük çözümler 2-4 mm'lik dönüşüm hataları eşliğinde Helmert transformasyonu ile ITRF sistemine taşınmıştır. $\mathrm{Bu}$ sistemde (3 boyutlu Kartezyen, XYZ) elde edilen koordinatlar, yersel yöntemlerden elde edilen yatay mesafe ve yükseklik ölçüleri ile karşılaştırabilmek amacıyla toposentrik (lokal, Kuzey, Doğu, Yukarı) koordinat sistemine dönüştürülmüştür. Elde edilen değerler Tablo 2'de sunulmaktadir.

Tablo 2. GAMIT/GLOBK yazılımından elde edilen koordinat kestirim sonuçları

\begin{tabular}{lllll}
\hline Kampanya Tarihi & İstasyon Adı & Kuzey $(\mathbf{m})$ & Doğu (m) & Yukarı (m) \\
\hline \multirow{2}{*}{2018} & KAME & 0 & 0 & 0 \\
110. günü & NKT1 & 102.466 & -38.247 & 21.819 \\
& NKT2 & 98.993 & -41.460 & 21.754 \\
& NKT3 & 101.150 & -44.960 & 21.898 \\
& NKT4 & 104.970 & -48.179 & 22.149 \\
2018 & KAME & 0 & 0 & 0 \\
111. günü & NKT1 & 102.453 & -38.253 & 21.825 \\
& NKT2 & 98.974 & -41.468 & 21.756 \\
& NKT3 & 101.143 & -44.965 & 21.894 \\
2018 & NKT4 & 104.961 & -48.187 & 22.158 \\
112. günü & KAME & 0 & 0 & 0 \\
& NKT1 & 102.473 & -38.243 & 21.818 \\
& NKT2 & 98.978 & -41.472 & 21.755 \\
& NKT3 & 101.144 & -44.960 & 21.900 \\
& NKT4 & 104.967 & -48.204 & 22.151 \\
\hline
\end{tabular}

Hassas Nokta Konumlama yöntemi ile yapılan analizler GAMP yazılımı kullanılarak statik modda ve GPS+GLONASS gözlemleri kullanılarak elde edilmiştir. Hassas saat ve yörünge parametreleri (final) GFZ kuruluşunun ftp adresinden yazılım tarafindan otomatik olarak indirilerek kullanılmaktadır. Analizler sonucunda elde edilen Kartezyen koordinatlar, KAME istasyonuna göre toposentrik (lokal) koordinat sistemine çevrilmiştir. Elde edilen sonuçlar Tablo 3'de sunulmaktadır.

\subsection{Klasik yersel yöntemlerden elde edilen sonuçların GNSS yöntemi ile karşılaştırılması}

HNK yönteminin doğruluğunu belirlemek amaciyla, Tablo 1'de verilen klasik yersel yöntemlerden elde edilen baz uzunluğu değerleri ve geometrik nivelmandan elde edilen yükseklik farkları baz alınacaktır. Rölatif konum belirleme yönteminden elde edilen değerler ise bir doğrulama unsuru olarak kullanılacaktır. 
Tablo 3. GAMP yazılımından elde edilen koordinat kestirim sonuçları

\begin{tabular}{lllll}
\hline Kampanya Tarihi & İstasyon Adı & Kuzey (m) & Doğu (m) & Yukarı (m) \\
\hline 2018 & KAME & 0 & 0 & 0 \\
110. günü & NKT1 & 102.460 & -38.145 & 21.822 \\
& NKT2 & 98.974 & -41.474 & 21.745 \\
& NKT3 & 101.143 & -45.013 & 21.835 \\
& NKT4 & 104.962 & -48.142 & 22.215 \\
\hline 2018 & KAME & 0 & 0 & 0 \\
111. günü & NKT1 & 102.477 & -38.194 & 21.708 \\
& NKT2 & 98.973 & -41.434 & 21.724 \\
& NKT3 & 101.142 & -44.987 & 21.790 \\
\hline 2018 & NKT4 & 104.969 & -48.228 & 22.137 \\
112. günü & KAME & 0 & 0 & 0 \\
& NKT1 & 102.459 & -38.204 & 21.774 \\
& NKT2 & 98.968 & -41.482 & 21.689 \\
& NKT3 & 101.146 & -44.909 & 21.854 \\
& NKT4 & 104.970 & -48.132 & 22.193 \\
\hline
\end{tabular}

$\mathrm{Bu}$ amaçla, GNSS yöntemlerinden (HNK ve rölatif) elde edilen Kuzey ve Doğu bileşen değerlerinden baz uzunlukları hesaplanmıştır.
Elde edilen değerlerin, Tablo 1'de verilen EUÖ'den elde edilen baz uzunluğu değerleri (S) ile farkları alınarak Tablo 4'de sunulmuştur.

Tablo 4. Rölatif ve HNK yöntemlerinden elde edilen baz uzunlukları değerleri ve bunların EUÖ ile elde edilen baz uzunluklarından (S) farkları

\begin{tabular}{lllllll}
\hline Kampanya Tarihi & D.N & B.N & $\begin{array}{l}\text { Rölatif } \\
(\mathbf{m})\end{array}$ & $\begin{array}{l}\text { HNK } \\
(\mathbf{m})\end{array}$ & $\begin{array}{l}\text { Rölatif-S } \\
(\mathbf{m m})\end{array}$ & $\begin{array}{l}\text { HNK-S } \\
(\mathbf{m m})\end{array}$ \\
\hline 2018 & KAME & NKT1 & 109.3713 & 109.3302 & -4.6 & -45.6 \\
110. günü & & NKT2 & 107.3245 & 107.3128 & 6.5 & -5.3 \\
& & NKT3 & 110.6909 & 110.7068 & -0.1 & 15.9 \\
& & NKT4 & 115.4988 & 115.4757 & -2.2 & -25.2 \\
\hline 2018 & KAME & NKT1 & 109.3617 & 109.3627 & -14.3 & -13.2 \\
111. günü & & NKT2 & 107.3097 & 107.2955 & -8.3 & -22.4 \\
& & NKT3 & 110.6879 & 110.6955 & -3.0 & 4.5 \\
& & NKT4 & 115.4935 & 115.5184 & -7.5 & 17.5 \\
\hline 2018 & KAME & NKT1 & 109.3767 & 109.3499 & 0.7 & -26.0 \\
112. günü & & NKT2 & 107.3154 & 107.3099 & -2.6 & -8.0 \\
& & NKT3 & 110.6865 & 110.6679 & -4.5 & -23.1 \\
& & NKT4 & 115.5065 & 115.4790 & 5.5 & -22.0 \\
\hline
\end{tabular}

Benzer olarak, GNSS yöntemlerinden elde edilen yukarı bileşen değerleri (Tablo 2 ve Tablo 3'de verilen) geometrik nivelmandan elde edilen yükseklik farkı değerleri (dh) ile farkları alınmak suretiyle karşılaştırılmıştır. Elde edilen sonuçlar Tablo 5'de sunulmaktadır. Elde edilen sonuçların bir bütün olarak ifade edilmesi amacıyla, GNSS yönteminden 2018 yilının 110. 111. ve 112 . günlerinde elde edilen toposentrik koordinat değerlerinin ortalaması alınarak, klasik yersel ölçümlerden elde edilen farklar ve standart sapmaları hesaplanmıştır. Elde edilen değerler Tablo 6'da sunulmuştur. 
Tablo 5. Rölatif ve HNK yöntemlerinden elde edilen Yukarı bileşen değerlerinin geometrik nivelmandan elde edilen değerlerden (dh) olan farkları

\begin{tabular}{lllll}
\hline Kampanya Tarihi & D.N & B.N & $\begin{array}{l}\text { Rölatif-G. Nivelman } \\
(\mathbf{m m})\end{array}$ & $\begin{array}{l}\text { HNK-G. Nivelman } \\
(\mathbf{m m})\end{array}$ \\
\hline 2018 & KAME & NKT1 & -15.0 & -11.8 \\
110. günü & & NKT2 & -12.6 & -21.8 \\
& & NKT3 & -12.0 & -74.9 \\
& NKT4 & 16.6 & 83.0 \\
\hline 2018 & KAME & NKT1 & -9.1 & -125.5 \\
111. günü & & NKT2 & -10.6 & -42.5 \\
& & NKT3 & -16.2 & -120.1 \\
& & NKT4 & 25.6 & 5.1 \\
\hline 2018 & & & -60.4 \\
112. günü & KAME & NKT1 & -16.0 & -77.7 \\
& & NKT2 & -11.7 & -55.7 \\
& & NKT3 & -10.1 & 60.7 \\
\hline
\end{tabular}

Tablo 6. Ortalama baz uzunluğu ve yükseklik farklarının klasik yöntemlerle karşılaştırılması

\begin{tabular}{|c|c|c|c|c|c|c|c|c|}
\hline & D.N & B.N & $\begin{array}{l}\text { Ort. Rölatif } \\
\text { (m) }\end{array}$ & $\begin{array}{l}\text { Ort. HNK } \\
\text { (m) }\end{array}$ & $\begin{array}{l}\text { Fark } \\
\text { Rölatif } \\
(\mathrm{mm})\end{array}$ & $\begin{array}{l}\text { Fark } \\
\text { PPP } \\
(\mathrm{mm})\end{array}$ & $\begin{array}{l}\text { Sigma } \\
\text { Röl. } \\
(\mathrm{mm})\end{array}$ & $\begin{array}{l}\text { Sigma } \\
\text { PPP } \\
(\mathrm{mm})\end{array}$ \\
\hline & KAME & NKT1 & 109.3699 & 109.3477 & -6.1 & -28.3 & \multirow{4}{*}{ \pm 2.20} & \multirow{4}{*}{ \pm 11.43} \\
\hline \multirow[t]{3}{*}{ Uzunluğu } & & NKT2 & 107.3166 & 107.3061 & -1.4 & -11.9 & & \\
\hline & & NKT3 & 110.6885 & 110.6901 & -2.5 & -0.9 & & \\
\hline & & NKT4 & 115.4996 & 115.4911 & -1.4 & -9.9 & & \\
\hline \multirow{4}{*}{$\begin{array}{l}\text { Yükseklik } \\
\text { farkı }\end{array}$} & KAME & NKT1 & 21.8207 & 21.7681 & -13.4 & -65.9 & \multirow{4}{*}{ \pm 16.46} & \multirow{4}{*}{ \pm 59.48} \\
\hline & & NKT2 & 21.7553 & 21.7197 & -11.7 & -47.3 & & \\
\hline & & NKT3 & 21.8973 & 21.8264 & -12.8 & -83.6 & & \\
\hline & & NKT4 & 22.1523 & 22.1816 & 20.3 & 49.6 & & \\
\hline
\end{tabular}

\section{Bulgular ve Tartışma}

Tablo 1'de verilen klasik yersel yöntemlerden elde edilen baz uzunluğu için doğruluk Nikon DTM-322 marka ve modelli EUÖ'in kullanma k1lavuzunda verilen $\pm(3+2 \mathrm{ppm} \times \mathrm{D}) \mathrm{mm}$ formülü ile hesaplandığında yaklaşık 100 metre için $\pm 3.2 \mathrm{~mm}$ elde edilmiştir. Geometrik nivelman yöntemiyle gidiş-dönüş şeklinde elde edilen yükseklik farkları için ise hassasiyetin birkaç milimetre seviyelerinde olduğu genel kabuldür. Söz konusu değerler oldukça yüksek hassasiyet seviyeleri olup, rölatif ve HNK GNSS analiz yöntemlerinin doğruluğu hakkında fikir edinmek üzere karşılaştırma amacıyla kullanılmıştır.

Ardışık üç güne ait baz uzunluğu değerlerinin karşılaştırıldığ 1 Tablo 4 incelendiğinde, rölatif konumlama (6. sütun) için değerlerin $0-14 \mathrm{~mm}$ arasında dalgalandığı, HNK yöntemi (7. sütun) için ise değerlerin $5-45 \mathrm{~mm}$ seviyelerinde değişiklik gösterdiği görülmektedir.

Benzer bir karşılaştırmanın yükseklik bileşeni için yapıldığ 1 Tablo 5 incelendiğinde rölatif konumla yöntemi için fark değerlerinin, 9-18 mm seviyelerinde değişiklik gösterdiği, HNK yöntemi için ise farkların 1-12 cm seviyelerinde dalgalandığı görülmektedir.

Ardışık üç günden elde edilen sonuçların ortalamaların verildiği Tablo 6 incelendiğinde, rölatif konum belirleme için farkların baz bileşeni için 1- $6 \mathrm{~mm}$ arasında değiştiği, düşey bileşen için ise $11 \mathrm{~mm}$ ile $16 \mathrm{~mm}$ arasında olduğu görülmüştür. Söz konusu farklara ait standart sapma değerleri ise baz bileşeni ve düşey bileşen için sırasıyla, $\pm 2.20 \mathrm{~mm}$ ve $\pm 16.46 \mathrm{~mm}$ olarak hesaplanmıştır. Fark değerleri HNK yöntemi için baz uzunluğunda $8-28 \mathrm{~mm}$ arasında değişmekte, 
düşey bileşen için ise $50-80 \mathrm{~mm}$ seviyelerinde olduğu görülmektedir. $\mathrm{Bu}$ değerlere ait standart sapma değerlerinin, baz uzunluğunda $\pm 11.43 \mathrm{~mm}$, düşeyde bileşende ise $\pm 59.48 \mathrm{~mm}$ seviyelerinde olduğu görülmektedir.

\section{Sonuç ve Öneriler}

Bu çalışmada 5 noktalı bir mikro-jeodezik ağda yapılan 8 saatlik GNSS gözlemleri kullanılarak HNK yönteminin doğruluğu, yüksek doğrulukta elde edilen klasik yersel ölçümlerden elde edilen sonuçlarla karşılaştırılarak belirlenmiştir. Çalışmada yapılan analizler sonucunda aşağıdaki sonuçlara ulaşılmıştır.

Rölatif konum belirlemede elde edilen yatayda $\pm 2.20 \mathrm{~mm}$ ve düşeyde $\pm 16.46 \mathrm{~mm}$ seviyelerindeki standart sapma değerleri, 8 saatlik gözlemler için beklenen seviyelerde olup, çalışmada kullanılan GNSS gözlemlerinin, HNK yönteminin doğruluğunun araştırılması için yeterli kalitede olduğunu ortaya koymuştur.

HNK yönteminin doğruluğu, 8 saatlik gözlemler ve günümüzde elde edilen hassas saat ve yörünge parametreleri (final) eşliğinde yatayda $1 \mathrm{~cm}$, düşeyde ise 5-6 cm seviyelerinde olduğu sonuçlarına varılmıştır. Ancak, bu çalışmanın dağlık bir bölgede yapılması ve noktaların yere yakın tesis edilmesi zorunlulukları göz önüne alındığında, elde edilen ölçülerin sinyal yansıması hatasından etkilenmemesi kaçınılmaz olmuştur. $\mathrm{Bu}$ nedenle, bu çalışmada elde edilen sonuç değerlerinin özellikle düşey bileşen için olması gerekenin üstünde olduğu dikkate alınmalıdır.

\section{Kaynaklar}

Abd-Elazeem, M., Farah, A. ve Farrag, F., 2011. Assessment study of using online (CSRS) GPSPPP Service for mapping applications in Egypt. Journal of Geodetic Science, 1(3), pp.233-239.

Alkan, R.M., Saka, M.H., Ozulu, İ.M. ve İlçi, V., 2017. Kinematic precise point positioning using GPS and GLONASS measurements in marine environments. Measurement, 109, pp.36-43.

Bahadur, B. ve Nohutcu, M., 2018. PPPH: a MATLAB-based software for multi-GNSS precise point positioning analysis. GPS Solutions, 22(4), p.113.

Bisnath, S. ve Gao, Y., 2009. Current state of precise point positioning and future prospects and limitations. In Observing our changing earth (pp. 615-623). Springer, Berlin, Heidelberg.
Cai, C., Gao, Y., Pan, L. ve Zhu, J., 2015. Precise point positioning with quad-constellations: GPS, BeiDou, GLONASS and Galileo. Advances in space research, 56(1), pp.133-143.

Herring, T. A., R. W. King, ve S. McClusky. 2019. "GPS processing program suites: GAMIT/GLOBK V10.7.” MIT

Marques, H.A., Marques, H.A.S., Aquino, M., Veettil, S.V. ve Monico, J.F.G., 2018. Accuracy assessment of Precise Point Positioning with multi-constellation GNSS data under ionospheric scintillation effects. Journal of Space Weather and Space Climate, 8, p.A15.

Nikon, (2019, 15 Mart), DTM-322 kullanma kılavuzu https://www.manualslib.com/manual/1216908/ Nikon-Total-Station-Dtm-322.html

Shi, C., Gu, S., Lou, Y. ve Ge, M., 2012. An improved approach to model ionospheric delays for single-frequency precise point positioning. Advances in Space Research, 49(12), pp.16981708.

Su, K. ve Jin, S., 2018. Improvement of Multi-GNSS Precise Point Positioning Performances with Real Meteorological Data. The Journal of Navigation, 71(6), pp.1363-1380.

Yao, Y., Zhang, R., Song, W., Shi, C. ve Lou, Y., 2013. An improved approach to model regional ionosphere and accelerate convergence for precise point positioning. Advances in Space Research, 52(8), pp.1406-1415.

Yiğit, C.Ö., Kızılarslan, M. ve Çalışkan, E., 2016. GPS-PPP ve GPS/GLONASS-PPP Yöntemlerinin Konum Belirleme Performanslarının Ölçü Süresine Bağlı Olarak Değerlendirilmesi. Harita Teknolojileri Elektronik Dergisi, 8(1), pp.22-39.

Zhou, F., Dong, D., Li, W., Jiang, X., Wickert, J. ve Schuh, H., 2018. GAMP: An open-source software of multi-GNSS precise point positioning using undifferenced and uncombined observations. GPS Solutions, 22(2), p.33. 